\title{
Optical Emission of Atmospheric - Pressure Dielectric Barrier Discharge Plasma on Mercury Diiodide/Rare Gases Mixtures
}

\author{
A.A. Malinina, A.K.Shuaibov, A.N. Malinin \\ UzhgorodNationalUniversity, Pidgirna str. 46, 88000, Uzhgorod, Ukraine
}

\begin{abstract}
New results of research of spectral and electrical characteristics of the plasma high-frequency atmospheric - pressure dielectricbarrier discharge (DBD) at mixtures of mercury diiodide vapor with xenon and neon are presented. Gas-discharge plasma creation and excitation of the working mixture components was carried out by sinusoidal form voltage at a repetition rate $125 \mathrm{kHz}$. Simultaneous emission of mercury monoiodideexciplex molecules $\left(B^{2} \Sigma_{1 / 2}^{+} \rightarrow X^{2} \Sigma^{+}{ }_{1 / 2}, \quad C^{2} \Pi_{1 / 2} \rightarrow X^{2} \Sigma_{1 / 2}^{+}\right)$, xenon iodide $\left(B^{2} \Sigma_{1 / 2}^{+} \rightarrow X^{2} \Sigma_{1 / 2}^{+}\right.$, $D_{I / 2} \rightarrow A^{2} \Pi_{1 / 2}$ ) and iodine $\left(D^{\prime} \rightarrow A^{\prime}\right)$ have been revealed. On the basis of comparing the experimental data of the behavior of the spectra $B-X$ and $C-X$ transitions of molecule HgI and depending on the component composition the mechanism of emission brightness enhancement of exciplex molecule HgI in mixtures with addition of xenon have been defined and conclusions about the mechanism of exciplex molecules HgI, XeI and $\mathrm{I}_{2}$ formation in the discharge have been made. High-frequency atmospheric - pressure barrier discharge on mercury diiodide vapor with xenon and neon mixture is of interest for use in excilampthat emits simultaneously spectral bands in the violet - blue and ultraviolet spectral ranges.
\end{abstract}

Keywords:dielectricbarrier discharge, high-frequency,radiation, atmospheric- pressure plasma, mercury diiodidevapor,xenon, neon.

\section{Introduction}

Creation of new optical radiationsources, including excimer (or exciplex), that are important in modern science and technology requires the studies of optical emission and parameters of the working media of such sources [1-3].Plasma in the mixtures of mercury diiodidevapor with atomic and molecular gases is an efficientexciplex source of coherent and spontaneous emission in the violet-blue range of the spectrum with a maximum emission at wavelengths $\lambda_{\max .}=441.4,443,444,445 \mathrm{~nm}$ [4-12]. Exciplex radiators (lasers and excilamps) that work on such mixtures provide high spectral radiation power that is important for practical applications in plant photoregulation, biotechnology and medicine. [13-14].Optical emission of gaseous mixtures, including mercury diiodidevapor, inert gases, molecular nitrogen was studied in [4-11]. Atmospheric pressure plasma in the working mixtures was produced in a glow and barrier discharges under repetitively pulsed or sinusoidalvoltage form. High radiation efficiency demonstrated recently for gas mixtures containing mercury diiodide vapor, helium and xenonin the studies in which the experiments were carried out under pulsed pumping (pulse duration $\leq 150$ nanoseconds) at a frequency $1-20 \mathrm{kHz}$ [10 - 12].Creation more powerful emitters (excilamps) in this spectral range requires (makes it necessary) carrying out diagnostics of optical emission of atmospheric pressure plasma on mercury diiodide vapor, neon and xenon mixtures at high pumping frequencies (over $20 \mathrm{kHz}$ ) of working mixtures, which was the purpose of our research.

\section{Experimental Setup}

The experimental setup for the study of atmospheric pressure dielectric barrier discharge (DBD) plasma, initiated by the sinusoidal form of pump pulses in mixtures of mercury diiodide vapor with inert gases neon and xenon was close to that used by us for the investigation of atmospheric-pressure dielectric barrier discharge plasma with mixtures of mercury dibromide vapor with inert gases [15].

For the experiments a small cylindrical radiator (figure 1) with one dielectric barrier (1) with a capacity $C_{d}=40$ $\mathrm{pF}$, made of a quartz tube was used. The molybdenum electrode (2) with a diameter of 1 mmwaslocated

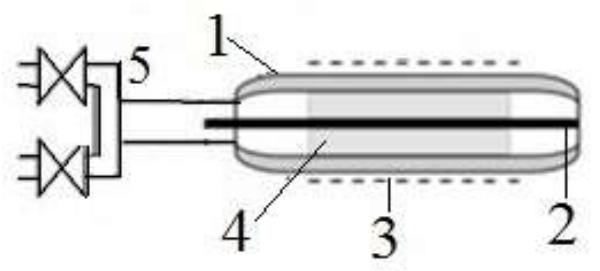

Figure1. Radiator: 1- quartz tube, 2-internal electrode, 3 - external electrode (mesh), 4 -discharge gap, 5pumping system and a gas inlet. 
axially inside. The outer diameter of the radiator (tube) was equal to $6 \mathrm{~mm}$, wall thickness - $1 \mathrm{~mm}$. The discharge gap (4) was $1.5 \mathrm{~mm}$. The outer electrode of $30 \mathrm{~mm}$ in length (3) is made of mesh with radiation transmittance T $=70 \%$. At the end of the quartz tube was located the capillary (5) with a diameter of $1.5 \mathrm{~mm}$, which served to pump the radiator, filling it with working mixtures, as well as to reduce the removal of mercury diiodide vapors fromradiator in the pumping system. The dielectric barrier discharge was excited at a total pressure of a mixture of $110.6-110.7 \mathrm{kPa}$. The high-voltage generator allowed changing the amplitude and frequency of the applied voltage to the electrodes of sinusoidal form up to $3 \mathrm{kV}$ and $125 \mathrm{kHz}$, respectively. Discharge emission was analyzed in the spectral range $200-900 \mathrm{~nm}$. The spectral resolution of the registration system was 0.05 $\mathrm{nm}$. Working mixtures were prepared directly in the radiation source. Mercury diiodide $\left(\mathrm{HgI}_{2}\right)$ in an amount of 60 mg pre-loaded into the radiator. After loading the salt dehydration and outgassing of the internal surface of the source by heating at a temperature of $70-100^{\circ} \mathrm{C}$ and pumping during 2 hours was carried out.The partial pressure of gases was measured with an accuracy of $10 \mathrm{~Pa}$. The value of the partial pressure of the vapor $\mathrm{HgI}_{2}$ was determined by the temperature at the coldest point of the radiator based on the interpolation reference data of [16] and in our conditions was equal to600 - $700 \mathrm{~Pa}$.

\section{Results And Discussion}

Spectral and electrical characteristics of the plasma high-frequency barrier discharge were studied in mixtures of the following compositions: $\mathrm{HgI}_{2}: \mathrm{Ne}$ and $\mathrm{HgI}_{2}: \mathrm{Xe}$ : Ne. In the initial stage (first $20-30 \mathrm{~s}$ ) the discharge color was dependent on the component composition of the mixture. In a binary mixture with neon red color prevailed, while xenon supplements appeared blue. As the self-heating of the mixture discharge color becomes bright blue. After the initiation of the DBDmany avalanche-streamer mechanism of discharge burningwas observed, typical for frequency $\sim 100 \mathrm{kHz}$ - a set of conical micro-discharges with vertex at the electrode and the base on the inner surface of the quartz tube[17]. With increasing temperature, the discharge becomes more diffuse and uniform,the contrast brightness smoothed noticeably in volume discharge and filaments.Figure 2 shows a typical waveform of current and voltage. In each half-cycle of the applied voltage on the waveform of the recorded current on the current bias curve observed series of sharp bursts of different amplitude and approximately the same duration. Bursts on current waveform reflect the value of the conduction current in the discharge. Each current burst is due to the number of threadlikemicro discharges-filaments that occur in the discharge gap and are randomly distributed in time.For a mixture $\mathrm{HgI}_{2}$ : $\mathrm{Ne}$ the peaks amplitude has not exceeded $10 \mathrm{~mA}$ when the duration was 50-80 ns. The first burst of current with increasing external voltage amplitude (U) all moved to the left of the applied voltage maximum and at large amplitudes U first burstalready fittedto the negative phase of the applied voltage. Current bursts of positive polarity always fitted to voltage phase withpositive derivative $\mathrm{dU} / \mathrm{dt}>0$.The number of current burstsincreased while the voltage raised.The end of the last

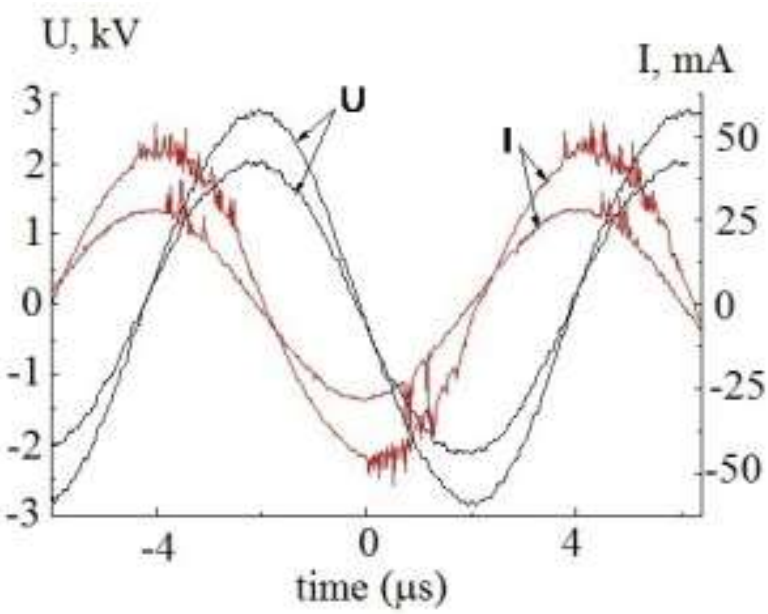

Figure 2. Oscillograms of voltage and current pulses of a barrier discharge in the mixture $\mathrm{HgI}_{2} / \mathrm{Ne}=0.6 / 110$ $\mathrm{kPa}$ at $\mathrm{f}=125 \mathrm{kHz}$ for different values of the voltage applied.

pulse coincided with the maximum of applied voltage, i.e., the discharge continued as long as the instantaneous voltage value on the electrode system did not reach $\mathrm{U}$.

At the same valueUat the DBDon $\mathrm{HgI}_{2}$ :Xe: Ne mixtures, breakdown occurred at 150-200 ns earlieras on the $\mathrm{HgI}_{2}$ : Ne mixture. With the growth of voltage $\mathrm{U}$. the active component gives an increasing contribution to the total current. The maximum value of the conduction current in the DBD at $\mathrm{HgI}_{2}: \mathrm{Xe}$ : Nemixture at an operating temperature $170{ }^{\circ} \mathrm{C}$ was equal to $15 \mathrm{~mA}$. 
Survey DBD plasma emission spectra in the $\mathrm{HgI}_{2}: \mathrm{Ne}$ and $\mathrm{HgI}_{2}: \mathrm{Xe}: \mathrm{Ne}$ mixtures at $\mathrm{f}=125 \mathrm{kHz}$ are shown in figure 3 and figure 4 . As can be seen in the spectra in the visible range dominates the system of bands with a peak at $\lambda=443 \mathrm{~nm}$, which has weakly allowed vibrational structure and corresponds to the electronvibrational transition $\mathrm{B}^{2} \Sigma^{+}{ }_{1 / 2} \rightarrow \mathrm{X}^{2} \Sigma^{+}{ }_{1 / 2}$ of mercury monoiodide molecules [18].

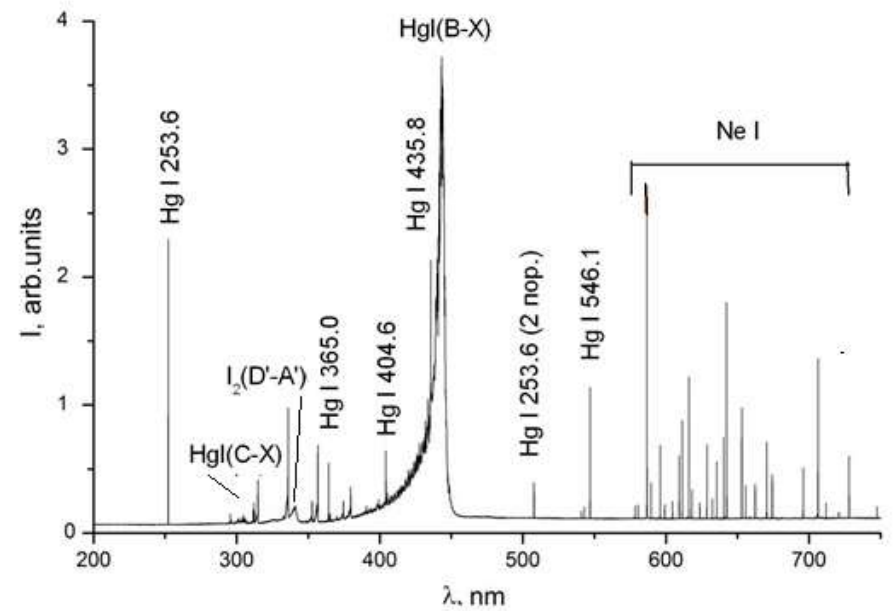

Figure 3. Survey emission spectrum of barrier discharge plasma based on the mixtures $\mathrm{HgI}_{2} / \mathrm{Ne}=0.6 / 110 \mathrm{kPa}$.

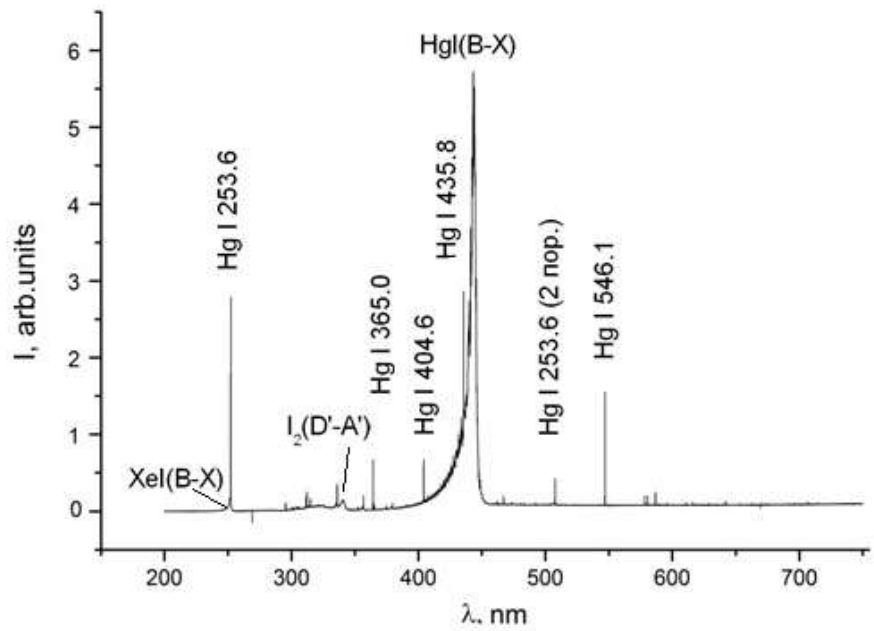

Figure 4.. Survey emission spectrum of barrier discharge plasma based on the mixtures $\mathrm{HgI}_{2} / \mathrm{Xe} / \mathrm{Ne}=$ $0.7 / 10 / 100 \mathrm{kPa}$.

For this band system characteristic is a sharp increase in intensity from the long-wavelengthregion and a slow decrease in the short-wavelength region.In terms of atmospheric pressure barrier discharge edges of the spectral bands overlap the range of wavelengths 350-450 nm.In the mixture $\mathrm{HgI}_{2}: \mathrm{Ne}=0.7: 100 \mathrm{kPa}$ (figure 3), in addition to these spectral bands in the range $580-740 \mathrm{~nm}$ observed sufficiently intense lines of neon atoms.In all spectra were registered the radiation of $\mathrm{HgI}$ molecules $(\mathrm{C} \rightarrow \mathrm{X})$ with a maximum at $\lambda=306 \mathrm{~nm}$, the radiation of decay products of mercury diiodide -the band of molecular iodine $\mathrm{I}_{2}\left(D^{\prime} \rightarrow A^{\prime}\right)$ with a maximum at $\lambda=342$ $\mathrm{nm}$ and lines of atomic mercury in UV and visible range, the most intensiveof which are $-253.6\left(6^{3} P_{1} \rightarrow 6^{1} S_{0}\right)$, $365.0\left(6^{3} D_{3} \rightarrow 6^{3} P_{2}\right), 404.6\left(7^{3} S_{1} \rightarrow 6^{3} P_{0}\right), 435.8\left(7^{3} S_{1} \rightarrow 6^{3} P_{1}\right)$ and $546.1 \mathrm{~nm}\left(7^{3} S_{1} \rightarrow 6^{3} P_{2}\right)[18,19]$.

The addition to the mixture $\mathrm{HgI}_{2}$ : $\mathrm{Ne}$ of xenon led to a significant change in the plasma emission spectrum DBD. For this mixture $\left(\mathrm{HgI}_{2}: \mathrm{Xe}: \mathrm{He}=0.7: 10: 100 \mathrm{kPa}\right)$ is characteristic that in the emission spectrum, in addition to systems of spectral bands $\mathrm{HgI}(\mathrm{B} \rightarrow \mathrm{X})$ and $\mathrm{HgI}(\mathrm{C} \rightarrow \mathrm{X})$, are present $\mathrm{Xe}$ atoms lines at $\lambda=462.4$ $\mathrm{nm}\left(7 \mathrm{p}[3 / 2]_{2} \rightarrow 6 \mathrm{~s}[3 / 2]_{2}^{0}\right), \lambda=467.1 \mathrm{~nm}\left(7 \mathrm{p}[5 / 2]_{3} \rightarrow 6 \mathrm{~s}[3 / 2]_{2}^{0}\right), \lambda=823.1 \mathrm{~nm}\left(6 \mathrm{p}[3 / 2]_{2} \rightarrow\right.$ $\left.6 \mathrm{~s}[3 / 2]_{2}^{0}\right)$ and $\lambda=828 \mathrm{~nm}\left(6 \mathrm{p}[1 / 2]_{0} \rightarrow 6 \mathrm{~s}[3 / 2]_{1}^{0}\right)[19,20]$. Also the emission bands of exciplex molecules $\mathrm{XeI}(B \rightarrow X)$ and $\mathrm{XeI}(D \rightarrow A)$ with maxima at 253 and $320 \mathrm{~nm}$ were observed, respectively (figure 4). Compared 
with a mixture $\mathrm{HgI}_{2}$ : $\mathrm{Ne}, \mathrm{Ne}$ atomic line intensity at $580-750 \mathrm{~nm}$ decreased to about 1-2 times, while the emission brightnessHgI $(B \rightarrow X)$ increased by 1.6 times, and the brightness $\operatorname{HgI}(C \rightarrow X)$ decreased by 1.8 times. Under molecularband brightness understood spectrum in the area under the curve.

The most intense spectral bands and plasma emission lines on a mixture of mercurydiiodide vapor with neon and xenon for the pump pulse repetition frequency $125 \mathrm{kHz}$, the relative brightness and intensity based on the spectral sensitivity of the registration system $\left(\mathrm{J} / \mathrm{k}_{\lambda}\right)$, and also the excitation energy is given in table. Data on the excitation energies were taken from works [18-23].

Table. Bands and lines of barrier discharge plasma radiation in mixtures of mercury diiodide vapor with neon

\begin{tabular}{|c|c|c|c|c|}
\hline \multirow[t]{2}{*}{$\overline{\lambda, \mathrm{nm}}$} & \multirow[t]{2}{*}{ Molecule, atom } & \multicolumn{2}{|l|}{$\mathrm{J} / \mathrm{k}_{\lambda}$,arb.units } & \multirow[t]{2}{*}{$E_{\mathrm{e}}, \mathrm{eV}$} \\
\hline & & $\begin{array}{l}\mathrm{HgI}_{2} / \mathrm{Ne}= \\
0.6 / 110 \mathrm{kPa}\end{array}$ & $\begin{array}{l}\mathrm{HgI}_{2} / \mathrm{Xe} / \mathrm{Ne}= \\
0.7 / 10 / 100 \mathrm{kPa}\end{array}$ & \\
\hline 253 & $\mathrm{XeI}(B \rightarrow X)$ & - & 6.55 & $4.85[21]$ \\
\hline 253.6 & $\mathrm{HgI}$ & 1.3 & 2.02 & $4.88[20]$ \\
\hline 306 & $\operatorname{HgI}(C \rightarrow X)$ & 10.0 & 4.78 & $8[18]$ \\
\hline 320 & $\mathrm{XeI}(B \rightarrow A)$ & - & 2.05 & $4.85[21]$ \\
\hline 342 & $\mathrm{I}_{2}$ & 17.34 & 22.93 & $5[21]$ \\
\hline 365.0 & $\mathrm{Hg} \mathrm{I}$ & 0.55 & 0.93 & $8.86[20]$ \\
\hline 404.6 & $\mathrm{Hg} \mathrm{I}$ & 0.50 & 0.88 & $7.73[19]$ \\
\hline 435.8 & $\mathrm{Hg} \mathrm{I}$ & 0.58 & 0.97 & $7.73[19]$ \\
\hline 443 & $\operatorname{HgI}(B \rightarrow X)$ & 88 & 141 & $7[18,22]$ \\
\hline 462.4 & Xe I & - & 0.2 & $11.00[20,23]$ \\
\hline 467.1 & Xe I & - & 0.21 & $10.97[20,23]$ \\
\hline 546.1 & $\mathrm{Hg} \mathrm{I}$ & 0.58 & 1.42 & $7.73[20]$ \\
\hline 585.2 & $\mathrm{Ne} I$ & 0.88 & 0.08 & $18.97[20,23]$ \\
\hline 640.2 & $\mathrm{NeI}$ & 0.63 & 0.02 & $18.55[20,23]$ \\
\hline 703.2 & $\mathrm{Ne} I$ & 0.57 & 0.02 & $18.38[20,23]$ \\
\hline 823.1 & $\mathrm{Xe} \mathrm{I}$ & - & 1.2 & $9.82[20,23]$ \\
\hline 828 & Xe I & - & 0.5 & $9.94[20,23]$ \\
\hline
\end{tabular}

The emission of observed spectral transitions may be initiated by the following reactions [24-31]:

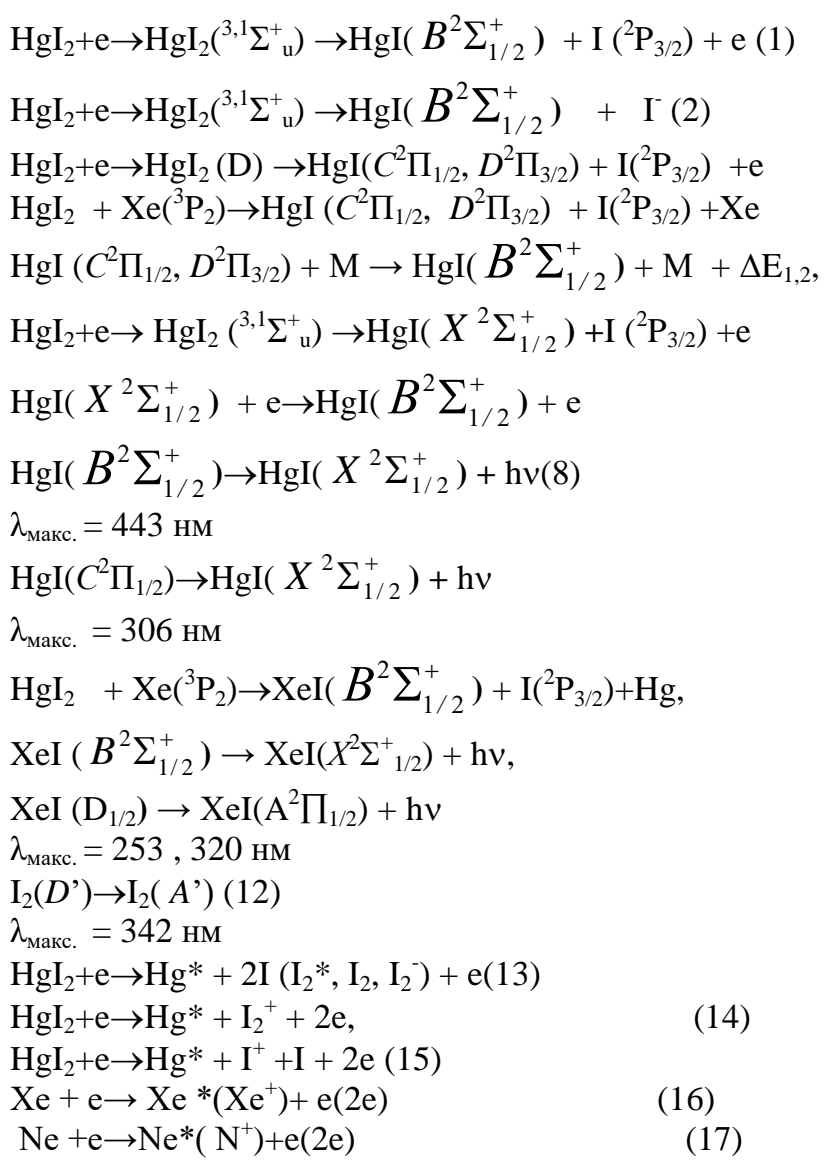


$\mathrm{Xe}^{*}\left(\mathrm{Xe}_{2}{ }^{*}\right)+\mathrm{I}_{2} \rightarrow \mathrm{XeI}\left(B^{2} \Sigma_{1 / 2}^{+}\right)+(\mathrm{Xe})+\mathrm{I}(18)$

$\mathrm{Xe}^{+}\left(\mathrm{Xe}_{2}{ }^{+}, \mathrm{Xe}_{3}{ }^{+}\right)+\mathrm{I}_{2}^{-}+\mathrm{M} \rightarrow \mathrm{XeI}\left(B^{2} \Sigma_{1 / 2}^{+}\right)+\mathrm{I}+(\mathrm{Xe}, 2 \mathrm{Xe})+\mathrm{M}(19)$

$\mathrm{Xe}^{+}+\mathrm{I}^{-}+\mathrm{M} \rightarrow \mathrm{XeI}\left(B^{2} \Sigma_{1 / 2}^{+}\right)+\mathrm{M}$,

where $\mathrm{M}$ - concentrations of quenching molecules or atoms $\left(\mathrm{HgI}_{2}, \mathrm{Xe}, \mathrm{Ne}\right), \Delta \mathrm{E}_{1,2}$ - the energy difference between the states $C^{2} \Pi_{1 / 2}, D^{2} \Pi_{3 / 2}$ and $B^{2} \Sigma_{1 / 2}^{+}$molecules HgI.

Reactions (1) and (2) are known as major sources of $\mathrm{HgI} *$ molecules, effective cross section for which is equal the value (1.2 -3.0) $\times 10^{-17} \mathrm{~cm}^{2}$ [24-25]. In addition, mercury monoiodide can be formed in the reaction (3) as a result of mercury diiodide molecules excitation in the state D under collisions with electrons (D - the state is the sum of a number of states, which are located between $5.7 \mathrm{eV}$ and $9.5 \mathrm{eV}$ (ionization threshold $\mathrm{HgI}_{2}$ ) [26 - 28].Emission from the $\mathrm{D}$ - state $\mathrm{HgI}_{2}$ molecules is not observed, as this state quickly dissociateswith formation of electronically excited molecules $\mathrm{HgI} *$ to $\mathrm{C}^{2} \Pi_{1 / 2}, \mathrm{D}^{2} \Pi_{3 / 2}$ - states [27]. These states are excited also by mercury diiodide molecules collisions with xenon atoms in the metastable state $\left({ }^{3} \mathrm{P}_{2}\right)$ in the reaction (4).In the reaction (5) they relax with high efficiency in mercury monoiodidestate $B^{2} \Sigma_{1 / 2}^{+}$[27].

Reaction (6) is another dissociation channel of mercury diiodide molecules compared to reaction (1), wherein a rate constant is equal to $2.5 \times 10^{-11} \mathrm{~cm}^{3} \mathrm{~s}^{-1}$ [29]. When electrons collide with mercury monoiodide molecules in ground state there $B^{2} \Sigma_{1 / 2}^{+}$stateexcites (reaction 7), rate constantof which is equal to $2.7 \times 10^{-}$ ${ }^{7} \mathrm{~cm}^{3} \mathrm{~s}^{-1}$ [30]. Electron-vibrational transitions $B^{2} \Sigma_{1 / 2}^{+} \rightarrow\left(X^{2} \Sigma_{1 / 2}^{+}\right)$and $\left(C^{2} \Pi_{1 / 2}\right) \rightarrow\left(X^{2} \Sigma_{1 / 2}^{+}\right)$of mercury monoiiodide molecules lead to the emission of spectral bands $\left(\tau_{\mathrm{r}}=27.3 \times 10^{-9} \mathrm{~s}\right)$ with a maximum intensity at a wavelength $\lambda_{\max .}=443 \mathrm{~nm}$ (reaction (8)) and $\lambda_{\max }=306 \mathrm{~nm}$ (reaction (9)), respectively [18,31]. The reaction of the collision of xenon atoms in the metastable ${ }^{3} \mathrm{P}_{2}$ with the molecules of mercury diiodide (10) is possible, quite effective channel of the formation of exciplex molecules xenon iodide. Electron-vibrational transition $B^{2} \Sigma_{1 / 2}^{+}$ $\rightarrow\left(X^{2} \Sigma^{+}{ }_{1 / 2}, \mathrm{~A}^{2} \prod_{1 / 2}\right)$ of xenon iodide molecules leads to the emission of spectral bands with a maximum intensity at a wavelength $\lambda_{\text {max. }}=253 \mathrm{~nm}$ and $\lambda_{\max }=320 \mathrm{~nm}$ (reaction (11)[14,23]. The emission of spectral bands with a maximum intensity at a wavelength $\lambda_{\max }=342 \mathrm{~nm}$ is caused by electron-vibrational transitions $D^{\prime} \rightarrow A^{\prime}$ of iodine molecules (reaction 12), which are formed in the reaction (13) [14].The excited mercury atoms are formed due to the reaction $(13,14,15)$ due to the large effective cross section of dissociative excitation of mercury diiodide molecules by electrons.The emission of spectral lines of atoms and ions of xenon and neon caused by reactions $(16,17)$.

In addition to the reactions (10), the reactions (18-20) can be an effective source of exciplexesXeI

$\left(B^{2} \Sigma_{1 / 2}^{+}\right.$)formation.Reaction (18) is a harpoon reaction between $\mathrm{Xe}^{*}\left(\mathrm{Xe}_{2}\right)$ and $\left(\mathrm{I}_{2}\right)$ molecules, while (19-20) are ion - ion recombination $[14,23]$.

A possible reason for increase of emission brightness inHgI $(\mathrm{B} \rightarrow \mathrm{X})$ can be the difference in the plasma parameters in a mixture of mercury diiodide vapor, xenon and neon, in comparison with the mixture without xenon. For their study, we used a technique which is described in detail in $[15,32,33]$. As a result, an electronic concentration, rate constants of dissociative excitation of electrons of the molecules of mercury monoiodide (in these mixtures) and the distribution of the specific discharge power losses on these processes. Thevalueoftheelectrondensity $2.4 \cdot 10^{16} \mathrm{~m}^{-3}$ and $2.8 \cdot 10^{16} \mathrm{~m}^{-3}$, the mean electron energy of $9.8 \mathrm{eV}$ and $6.0 \mathrm{eV}$, the rate constant of the $\mathrm{B}^{2} \Sigma^{+}{ }_{1 / 2}^{-}$state excitation is equal to $2.2 \cdot 10^{-14} \mathrm{~m} 3 / \mathrm{s}$ and $1.2 \cdot 10^{-14} \mathrm{~m} 3 / \mathrm{s}$ for the experimental value of reduced electric field in plasma $(\mathrm{E} / \mathrm{N})=46 \mathrm{Td}$ and $49 \mathrm{Td}$ for $\mathrm{HgI}_{2}-\mathrm{Ne}$ and $\mathrm{HgI}_{2}-\mathrm{Xe}-\mathrm{Ne}$ gas mixtures, respectively. The distribution of the specific discharge power losses for the processes of dissociative excitation of mercury monoiodide molecules increase with increasing of $\mathrm{E} / \mathrm{N}$. For the $\mathrm{HgI}\left(\mathrm{B}^{2} \Sigma^{+}{ }_{1 / 2}\right)$ electronic states the losses reach their maximum values of $92 \%$ and $79 \%$ at $\mathrm{E} / \mathrm{N}=4.4 \mathrm{Td}$ for $\mathrm{HgI}_{2}-\mathrm{Ne}$ and $\mathrm{HgI}_{2}-\mathrm{Xe}-\mathrm{Ne}$ gas mixtures, respectively, and then as $\mathrm{E} / \mathrm{N}$ increases further, the power losses decrease (figure 5). Specific losses of discharge power for process of excitation of the metastable state ${ }^{3} \mathrm{P}_{2}$ of xenon atoms (figure 5, curve 3) have a similar dependence on the reduced electric field strength, reach a maximum $15 \%$, for the $\mathrm{E} / \mathrm{N}=11.2 \mathrm{Td}$. For the experimental value of the parameter $\mathrm{E} / \mathrm{N}=46 \mathrm{Td}$ and $49 \mathrm{Td}$, they are equal to the $10 \%$ and $7 \%$ respectively for $\mathrm{HgI}_{2}-\mathrm{Ne}$ and $\mathrm{HgI}_{2}-\mathrm{Xe}-\mathrm{Ne}$ gas mixtures, respectively. 


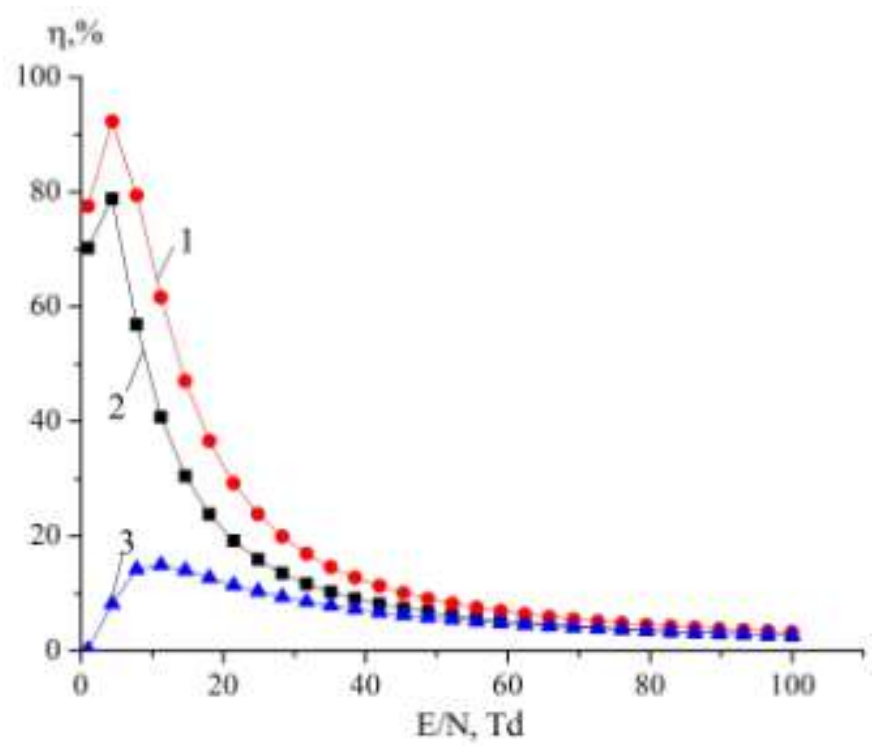

Figure 5. Specific discharge power losses for collisional interactions of electrons with mercury diiodide molecules and xenon atoms in the $\mathrm{HgI}_{2}-\mathrm{Ne}=0.54-99.46 \%$ mixture as function of $\mathrm{E} / \mathrm{N}(1)$ and in the $\mathrm{HgI}_{2}-\mathrm{Xe}-\mathrm{Ne} 0.64-9.03-90.33 \%$ mixture as function of $\mathrm{E} / \mathrm{N}(2)$ - dissociative excitation of the electronic states of mercury diiodide with the production of mercury monoiodide in the $\mathrm{B}^{2} \Sigma_{1 / 2}^{+}$state, (3) - excitation of the metastable state ${ }^{3} \mathrm{P}_{2}$ of xenon atoms.

Thus, these plasma parameters differ slightly depending on the composition of the mixture $\left(\mathrm{HgI}_{2}-\mathrm{Ne}\right.$ or $\mathrm{HgI}_{2}-\mathrm{Xe}-\mathrm{Ne}$ ) and therefore it is necessary to involve other processes that explain the significant increase in brightness of $\mathrm{HgI}$ radiation $(\mathrm{B} \rightarrow \mathrm{X}$ ) in a mixture of mercury diiodide vapor, xenon and neon (figure 4, table) in comparison with the mixture without xenon (figure 3, table). Such processes can be energy transfer to mercury diiodide molecules in collisions with xenon atoms in a metastable state $\left({ }^{3} P_{2}\right)$ and the process of quenching of $C^{2} \Pi_{1 / 2}, D^{2} \Pi_{3 / 2}$-states of mercury monoiodide molecules by xenon atoms with a nonradiative transition to the $B^{2} \Sigma^{+}{ }_{1 / 2}$-state $(4,5)$. Process (5) has been found in experiments on photodissociation of mercury diiodide [27, 34 , as well as in our experiments on $\mathrm{HgI}^{*}$ molecules excitation in terms of DBD on the mixture $\mathrm{HgI}_{2}-\mathrm{Xe}^{-} \mathrm{He}$ at the frequency of the pump pulse of the mixture up to $20 \mathrm{kHz}$ [12]. The obvious argument in favor of this is the decrease in brightness of $\mathrm{HgI}(\mathrm{C} \rightarrow \mathrm{X})$ bands system of radiation in mercury diiodide vapor, xenon and neon mixture in comparison with mercury diiodide vapor and neon mixture (table).

The sharp decrease in the intensity of the spectral lines of neon atoms in 580-750 $\mathrm{nm}$ range in this mixture can be explained by the process of Penning ionization of xenon [35]:

$$
\mathrm{Ne}^{*}+\mathrm{Xe} \rightarrow \mathrm{Ne}+\mathrm{Xe}^{+}+e
$$

In these experiments in the emission spectra was not manifested resonance line of the iodine atom at $\lambda$ $=206 \mathrm{~nm}$, due to absorption of radiation by molecules of mercury diiodide in the process [36]:

$\mathrm{HgI}_{2}+h v(206 \mathrm{HM}) \rightarrow \mathrm{HgI}_{2} *$

Thus, the numerical simulation results give the reason to conclude about the possibility to increase the radiation power in the violet-blue spectral range of the multi-wavelength DBD-driven exciplex lamp based on a mixture of the mercury diiodide vapor, xenon and neon by means of the reduction of the parameter E/N to the value of 4.4 Td. Thesimplestwaytoachievesuchvaluesistochangethe design ofthelamp, namelythe combination of pulse of high electric field on the front of the discharge and the low field behind the front.

\section{Conclusion}

The spectral and electrical characteristics of high-frequency $(125 \mathrm{kHz})$ atmospheric-pressure dielectric barrier discharge in mixtures of mercury diiodide vapor with neon and additives of xenon have been studied. Intense quasi-continuous emission with a maximum at $\lambda=443 \mathrm{~nm}$ of mercury monoiodideexciplex molecules, the main part of which is concentrated in the region 439-446 nm have been revealed. The optimum to obtain maximum emission of $\mathrm{HgI}$ molecules $(\mathrm{B} \rightarrow \mathrm{X})$ is a mixture $\operatorname{HgI}_{2}: \mathrm{Xe}: \mathrm{Ne}$. On $\mathrm{HgI}(\mathrm{B} \rightarrow \mathrm{X})$ bandssystem accounts for about $77 \%$ of the radiation of gas-discharge plasma of dielectric barrier discharge in the region of 
400 - 900 nm.Emission brightness of $\mathrm{HgI}(\mathrm{B} \rightarrow \mathrm{X})$ in dielectric barrier gas- discharge plasma in a mixture with the addition of xenon was increased in 1.6 times in comparison with a mixture $\mathrm{HgI}_{2}$ : Ne due to the presence of quenching processes of $\mathrm{C}^{2} \Pi_{1 / 2}$ and $\mathrm{D}^{2} \Pi_{3 / 2}$ states of mercury monoiodide molecules by Xe atoms and atomic collisions of xenon in ${ }^{3} \mathrm{P}_{2}$ metastable state with the molecules of mercury diiodide, that increases its population in $B^{2} \Sigma_{1 / 2}^{+}$state. The analysis of the distribution of energy in the internal degrees of freedom of the gas and the reaction rates of collisions with electrons for different electric field concluded that the combination of a high electric field pulse at the front of the discharge and the low field behind the front can be used to increase the emission intensity in mercury diiodide vapor with neon and xenon additives mixtures. Atmospheric - pressure dielectric barrier discharge onmulticomponentmixtures ofmercurydiiodidevaporwithgasescanbeusedtocreate self-heatinggasdischargeexcilampwhichemits spectral bandsintheviolet - blueandultravioletspectralranges. Theemissionofthisspectralbandscanbeeffectivelyusedtoactivatetheprocessofphotosynthesiswiththesimultaneousd estructionofvirusesandbacteria.

\section{References}

[1]. Zissis G and Kitsinelis S 2009 State of art on the science and technology of electrical light sources: from the past to the future $J$. Phys. D: Appl. Phys. 42173001

[2]. Kogelschatz U 2012 Ultraviolet excimer radiation from nonequilibrium gas discharges and its application in photophysics, photochemistry and photobiology J. Opt. Technol.79 484-93

[3]. Lomaev M I, Sosnin E A and Tarasenko V F 2012 Excilamps and their applications Prog. Quant. Electron. 36 51-97

[4]. Burnham R 1978 Dischargepumpedmercurichalidedissociationlasers.Appl. Phys. Lett.25 152-156

[5]. GavrilovaYuE, Zrodnikov VS, Klenentov AD and Podsosonnyi, AS 1980 ExcimerHgJ* laser excited by an electric dischargeQuant. Electron. 7 2495-2497

[6]. Konoplev AN, Kelman VA and SheveraVS 1983 Investigation into pulse discharge emission in $\mathrm{ZnI}_{2}, \mathrm{CdI}_{2}$ and $\mathrm{HgI}_{2}$ mixtures with helium and neonJ. Appl. Spectr.39 315-317.

[7]. Malinin A N 1997 Excitation of Mercury Monohalides in the Plasma of Pulse-Periodic Discharge in Mixtures of Mercury Dihalides and Rare Gases Laser Physics 71032- 1040

[8]. Malinin, A N, Polyak A V, Guivan N N, Zubrilin N Gand Shimon L L 2002 Coaxial HgI-excilamps. Qvant. Electron. 32 155- 159

[9]. Guivan N N, Malinin A N 2006 Characteristics of a high-frequency barrier discharge in mixtures of mercury diiodide vapor with gases Optics and Spectroscopy $101375-383$

[10]. MalininaA.A 2015 Diagnostics of optical characteristics and parameters of gas - discharge plasma based on mercury diiodide and helium mixture Open J. Appl. Sciences5, 826-832

[11]. Malinina A A, Malinin AN 2016 Optical Characteristics of a Gas Discharge Plasma Based on a Mixture of Mercury Diiodide Vapor, Nitrogen, and Helium J. Appl. Spectr.83592-597

[12]. Malinina A A, Malinin A.N. 2016 Experimental and theoretical characterization of dielectric barrier discharge in diode mercury, xenon andhelium gaseous mixtureAmerican J. Optics and Photonics 4 14-19

[13]. Romanenko V D, Krot Yu G, Sirenko L A and Solomatina V D 1999 Biotechnology of Hidrobion Cultivation (Kiev: Institute of Hydrobiology NAS Ukraine)

[14]. Boichenko A M, Lomaev M I, Panchenko A N,et al. Ultraviolet and Vacuum Ultraviolet Excilamps:Physics, Engineering, and Applications (STT, Tomsk,2011) [in Russian].

[15]. Guivan M.M., A.A. Malinina and A. Brablec 2011 Experimental and theoretical characterization of the multi-wavelength DBDdriven exciplex lamp operated with the mercury bromide/rare gases mixtures J. Phys. D: Appl. Phys. 44 1-11

[16]. Efimov A I, Belorukova L P, Vasil'kova I V, and Chechev V P 1983 Properties of Inorganic Compounds:Handbook (Leningrad: Khimiya)

[17]. Lomaev M I 2001 Definition of utility connection in excilamps with barrier discharge excitation Atmospheric and Ocean Optics14 1005-8

[18]. Pearse R W and Gaydon A G 1963 The Identification of Molecular Spectra (New York: Wiley)

[19]. Zaidel' A N, Prokof'ev V K, Raiskii S M, Slavnyi V A and Shreider E Ya 1977 Tables of Spectral Lines(Nauka: Moscow)

[20]. Prokop'ev V E, Yatsenko A S Preprint No. 16IAE SO AN SSSR (Institute of Atomic Energy, Siberian Branch, Russian Academy of Sciences, 1981)

[21]. Akishev YS, DemyanovAV, Karalnik VB, Pankin MV, TrushkinNI 2001Pulsed RegimeoftheDiffusiveModeof a BarrierDischargeinHeliumPlasmaPhysics Reports27 164-171

[22]. Malinin, A N, Shuaibov, AK and Shevera, V S 1983 Dissociative excitation of the $\mathrm{B}^{2} \Sigma^{+}{ }_{1 / 2}$ states of mercury monohalides by electron impact. Qvant. Electron. 10 1495-1496

[23]. Ch K. Rhodes 1979 Excimer Lasers (Berlin: Springer)

[24]. Kushawaha V, MahmoodM J 1987 Electronimpactdissociationof $\mathrm{HgX}_{2}$ (X=Cl, Br, IAppl. Phys.62 2173- 2177

[25]. MalininAN 1997ExcitationoftheB ${ }^{2} \Sigma^{+} / 1 / 2$-state ofmercurymonohalidesbyelectronimpact. Laser Phys.7 1168-1176

[26]. Nighan W.L., Brown R.T. 1982 Kinetic processes in the $\mathrm{HgBr}$. (B $\rightarrow \mathrm{X}) / \mathrm{HgB}_{\mathrm{r} 2}$ dissociation laser J.Appl.Phys. 53 7201 -7210

[27]. RoxloC ,MandlA 1980 Quenching kinetics for the $\operatorname{HgBr}\left(\mathrm{B}^{2} \Sigma_{1 / 2}\right)$ and $\operatorname{HgJ}\left(\mathrm{B}^{2} \Sigma_{1 / 2}, \mathrm{C}^{2} \Pi_{1 / 2}\right)$ states J. Chem. Phys, 72, 541-543

[28]. Wadt W.R. // J.Chem. Phys. 1980. V.72. №4. P. 2469

[29]. DatsyukV V, IzmailovI A and V V Naumov 2015 Emission kinetics of a HgBr discharge excilampUkr. J.Phys. 60 416-421

[30]. DatsyukV V, IzmailovI A, NaumovV V and KochelapV A 2016 Plasma Sources Sci. Technol. 25045020 (6pp)

[31]. Waynant R W, Iden J G $1978 \mathrm{HgX}$ (B) radiative lifetime by fast photolysis of $\mathrm{HgX}_{2}(\mathrm{X}=\mathrm{Br}, \mathrm{I})$ Appl. Phys. Lett.33 708 -710

[32]. Hagelaar G J M and Pitchford LC 2005 Solving the Boltzmann Equation to Obtain Electron Transport Coefficients and Rate Coefficients for Fluid ModelsPlasma Sources Sci Technol.14 722-733

[33]. http://www.bolsig.laplace.univ-tlse.fr/

[34]. Bazhulin S P, Basov N G, Bugrimov S N andetal. 1986Blue-violet $\mathrm{HgI}_{/} \mathrm{HgI}_{2}$ laserwith wide-bandopticalpumpingby a linearlystabilizedsurfacedischargeSovietJournalofQuantum Electronics16663-665

[35]. McDaniel E W and Nighan W L 1982 Gas Lasers (New York: Academic Press)

[36]. Jakob Maya 1977 Ultraviolet absorption cross sections of $\mathrm{HgI}_{2}, \mathrm{HgBr}_{2}$, and tin (II) halide vapors J. Chem. Phys. 67 4976-4980 